\title{
Characterization of Phytophthora infestans in Wisconsin from 1993 to 1995
}

\author{
K. D. Marshall-Farrar, Former Graduate Student, M. McGrath, Research Associate, R. V. James, Senior Research \\ Specialist, and W. R. Stevenson, Professor, Department of Plant Pathology, University of Wisconsin-Madison 53706
}

\begin{abstract}
Marshall-Farrar, K. D., McGrath, M., James, R. V., and Stevenson, W. R. 1998. Characterization of Phytophthora infestans in Wisconsin from 1993 to 1995. Plant Dis. 82:434-436.

Late blight of potato (Solanum tuberosum), caused by Phytophthora infestans, recently reappeared in Wisconsin and was a significant production problem in 1994. P. infestans isolates collected in Wisconsin from 1993 to 1995 were characterized for the following traits: mating type, sensitivity to metalaxyl, and allozyme genotype for Glucose-6-phosphate isomerase (Gpi). Characterization of these isolates revealed that a new, more aggressive population (A2 mating type, metalaxyl resistant, and Gpi genotype 100/111/122) is displacing the old population (A1 mating type, metalaxyl sensitive, and Gpi genotype 86/100) in Wisconsin.
\end{abstract}

Additional keyword: Ridomil

Phytophthora infestans (Mont.) de Bary, the cause of late blight of potato (Solanum tuberosum L.), appears periodically in Wisconsin when weather conditions are cool and wet during the growing season. Late blight was present in Wisconsin during 1993, 1994, and 1995. In 1993, its occurrence was sporadic, fungicide applications were effective, and losses were minimal. In 1994, however, Wisconsin's potato production sustained major losses due to late blight. Additional sprays for late blight control, unharvested fields, reduced yields, and tubers lost in storage totaled \$26 million in losses to the Wisconsin potato industry (W. R. Stevenson, unpublished data). Late blight was present but did not become a significant production problem in 1995 due to unusually high temperatures during July and August and careful attention by growers to disease management practices, including elimination of inoculum sources, crop scouting, weather monitoring, disease forecasting, and fungicide application.

A study to characterize $P$. infestans isolates collected in Wisconsin from 1993 to 1995 was initiated as a result of the recent reappearance of late blight in the state. The traits examined in this characterization study were mating type, sensitivity to metalaxyl,

Corresponding author: K. D. Marshall-Farrar E-mail: kdfarrar@ucdavis.edu

Current address of K. D. Marshall-Farrar: Department of Plant Pathology, University of California, 1 Shields Ave., Davis, CA 95616.

This paper includes a portion of the thesis submitted by K. D. Marshall-Farrar in partial fulfillment of the requirements for the M.Sc. degree.

Accepted for publication 29 December 1997.

Publication no. D-1998-0212-01R

(c) 1998 The American Phytopathological Society and allozyme genotype for Glucose-6-phosphate isomerase (Gpi). These traits have been intensively studied by other researchers as part of a critical analysis of population changes in $P$. infestans $(5-8,14,16)$.

\section{MATERIALS AND METHODS}

Culturing $P$. infestans isolates. Foliage and tubers of potato and foliage and fruit of tomato infected with late blight were sent by growers and homeowners throughout Wisconsin during 1993 to 1995 to our laboratory for diagnosis. P. infestans was isolated in pure culture from diseased plant material by several methods. Infected leaves were placed in glass petri dishes lined with moist filter paper and incubated in the dark at $20^{\circ} \mathrm{C}$ for $\approx 2$ days. Once sporulation was evident, a small piece of pea agar (9) was wiped over the sporangia (taking care to not touch the leaf surface) and transferred to a plate of pea agar. $P$. infestans was baited from potato tubers as follows: (i) decay from diseases other than late blight was cut away, (ii) remaining blighted tuber pieces were sliced several millimeters thick and placed in a moist chamber, and (iii) a disease-free surface-disinfested tuber slice (4 to $6 \mathrm{~mm}$ thick) was placed on top of the infected tuber slice. $P$. infestans mycelium quickly grew through the disease-free tuber, and isolations were made 5 to 7 days later as described above. P. infestans grown on pea agar plates was incubated in the dark at $20^{\circ} \mathrm{C}$ for growth and culture maintenance unless otherwise specified.

A single isolate corresponded to a single leaf lesion or infected tuber, and up to five isolates were collected per location. Cultures were grown on pea agar for the characterization studies but were grown on rye A agar slants (1) for storage lasting up to 6 months. In 1993 and 1994, pure cultures were necessary for the three components of the characterization study. In 1995, fungal material was obtained directly from sporulating leaf lesions or infected tubers for allozyme analyses, and inferences were made about mating type and metalaxyl sensitivity based on the Gpi genotype (Table 1). A random subsample (4 of 45) of 1995 leaf and tuber specimens was used to obtain pure cultures for analysis of mating type and metalaxyl sensitivity.

Mating type of $P$. infestans isolates. Mating type of isolates was determined by placing an unknown isolate and known A1 and A2 mating types in an equidistant triangular pattern on a pea agar plate. Hyphal interfaces were observed microscopically after 7 to 10 days of incubation. Abundant oospores appeared between the thalli of compatible mating types as a distinct thickened band. An area of hyphal repulsion existed between the thalli of incompatible mating types. If oospores formed between the unknown and A1 mating type but not between the unknown and A2 mating type, the unknown isolate was designated as an A2 mating type. If oospores formed between the unknown and A2 mating type but not between the unknown and A1 mating type, the unknown isolate was designated as an A1 mating type.

Metalaxyl sensitivity of $P$. infestans isolates. In 1993, a floating leaf disk assay was used to determine isolate sensitivity to metalaxyl. Healthy potato leaf disks, $\approx 15 \mathrm{~mm}$ in diameter, were inverted and floated on 0.1 and $1.0 \mu \mathrm{g} / \mathrm{ml}$ metalaxyl fungicide solutions (2). Control disks were floated on distilled water. Three replicates of each isolate (five leaf disks per replicate) were inoculated with a suspension of sporangia from sporulating plant material. After 7 to 9 days of incubation on a lab bench, leaf disks were examined for sporulation. Isolates were rated as sensitive when no sporulation was observed on disks floating on metalaxyl; intermediate when sporulation was observed on water and on metalaxyl at $0.1 \mu \mathrm{g} / \mathrm{ml}$ but not at $1.0 \mu \mathrm{g} / \mathrm{ml}$; and resistant when sporulation was observed on metalaxyl at both rates.

For all isolates in 1994 and the random subsample in 1995, sensitivity to metalaxyl was determined by a method modified from Shattock (13). Four isolates (4-mm-diameter agar plugs) were placed equidistantly around the edge of a 9-cm glass petri dish on unamended pea agar and pea agar amended with metalaxyl at 5 and $30 \mu \mathrm{g} / \mathrm{ml}$. After 6 days of growth, the mean radial growth of two replicates of each isolate was calculated. Sensitive, intermediate, and resistant ratings were assigned to isolates 
exhibiting $<10 \%, 10$ to $60 \%$, and $>60 \%$ growth, respectively, on metalaxyl-amended agar compared to growth on unamended agar.

Allozyme analysis of $\boldsymbol{P}$. infestans isolates. In 1994, mycelium of $P$. infestans isolates was grown in pea broth for 2 weeks and prepared for allozyme analysis by grinding fresh mycelial tissue as described in Goodwin and Fry (10). Starch gels were run for $\approx 14 \mathrm{~h}$ on a discontinuous histidine/ Tris-citrate buffer system at $130 \mathrm{~V}(25 \mathrm{~mA})$. Gel slices were stained for Gpi using an agar overlay described in Goodwin and Fry (10). Allozyme alleles, numerically designated relative to the most common allele, which was assigned a mobility of 100 (17), were identified by comparing banding patterns to known standards provided by W. E. Fry, Cornell University, Ithaca, NY. The interpretation of Gpi allozyme gels was described by Goodwin et al. (11).

In 1995, cellulose acetate electrophoresis (CAE) was employed to identify $G p i$ genotypes of $P$. infestans isolates. Goodwin et al. (11) determined that CAE provided better band resolution than traditional starch gel electrophoresis and was significantly less costly in both time and materials. Currently, populations of $P$. infestans in the United States and Canada are highly clonal, thus mating type and metalaxyl sensitivity are correlated with allozyme genotype (11). The four most commonly detected clonal lineages in the United States and Canada are described in Table 1 . Several Wisconsin isolates were run on both starch gel electrophoresis and CAE to demonstrate that the two methods yield the same results.

Table 1. Characteristics of the four dominant clonal lineages of Phytophthora infestans currently present in the United States and Canada ${ }^{a}$

\begin{tabular}{llccc}
\hline Genotype & \multicolumn{1}{c}{$\begin{array}{c}\text { Presence in } \\
\text { Wisconsin }\end{array}$} & Mating type & $\boldsymbol{G p i}^{\text {b }}$ genotype & $\begin{array}{c}\text { Response to } \\
\text { metalaxyl }\end{array}$ \\
\hline US-1 & $1993,1994,1995$ & A1 & $86 / 100$ & Sensitive \\
US-6 & Not observed & A1 & $100 / 100$ & Resistant \\
US-7 & 1993 & A2 & $100 / 111$ & Resistant \\
US-8 & 1994,1995 & A2 & $100 / 111 / 122$ & Resistant \\
\hline
\end{tabular}

${ }^{a}$ Adapted from Goodwin et al. (11).

${ }^{\mathrm{b}}$ Glucose-6-phosphate isomerase.

c US-1 also appeared periodically in Wisconsin prior to 1993.

Table 2. Response to metalaxyl and mating type distribution of Phytophthora infestans in Wisconsin during 1994

\begin{tabular}{lccc}
\hline & $\begin{array}{c}\text { \% of all } \\
\text { isolates }^{\mathbf{b}}\end{array}$ & \multicolumn{2}{c}{ Mating type distribution (\%) } \\
\cline { 3 - 4 }${\text { Response to } \text { metalaxyl }^{\mathbf{a}}}^{\text {Sensitive }}$ & 20 & 100 & $\mathbf{A 2}$ \\
Intermediate-sensitive & 2 & 100 & 0 \\
Intermediate & 39 & 12 & 0 \\
Resistant-intermediate & 35 & 0 & 88 \\
Resistant & 4 & 0 & 100 \\
\hline
\end{tabular}

${ }^{\text {a }}$ Response to metalaxyl was determined by comparing the radial growth of isolates on pea agar amended with metalaxyl at 5 and $30 \mu \mathrm{g} / \mathrm{ml}$ to growth on unamended pea agar. Sensitive $=<10 \%$ growth of control; intermediate $=10$ to $60 \%$ growth of control; resistant $=>60 \%$ growth of control. Intermediate-sensitive isolates were intermediate in response to metalaxyl at $5 \mu \mathrm{g} / \mathrm{ml}$ and sensitive at $30 \mu \mathrm{g} / \mathrm{ml}$. Resistant-intermediate isolates were resistant in response to metalaxyl at $5 \mu \mathrm{g} / \mathrm{ml}$ and intermediate at $30 \mu \mathrm{g} / \mathrm{ml}$.

${ }^{\mathrm{b}}$ A total of 85 isolates was tested. intermediate isolates were of the A1 mating type, and intermediate to resistant isolates were of the A2 mating type. In the 1995 subsample, three US-8 genotype isolates were intermediate and one US-1 genotype isolate was sensitive to metalaxyl.

Allozyme analysis of $\boldsymbol{P}$. infestans isolates. Four isolates analyzed for Gpi allozyme genotype in 1993 included two A1 isolates of the $86 / 100$ genotype (US-1), one A2 isolate of the 100/111 genotype (US-7), and one A2 isolate of the $111 / 122$ genotype (US-10) (12). In 1994, 85 isolates were analyzed for Gpi genotype. All A2 isolates were of the 100/111/122 genotype (US-8) and represented $73 \%$ of the isolates tested. The remaining A1 isolates were of the $86 / 100$ genotype (US-1). In 1995, 45 isolates were analyzed for allozyme genotype by CAE: 5 were US-1, and 40 were US- 8 .

\section{DISCUSSION}

The A1 mating type of $P$. infestans was dominant outside Mexico prior to the first known appearances of the A2 mating type in Europe and North America during the 1980s. The A2 mating type was first identified in the United States in 1987 (3). In 1993, the A2 mating type was detected for the first time in Wisconsin. However, metalaxyl effectively controlled late blight in most fields in 1993, suggesting isolates from those fields were the US-1 genotype. Isolates from 1993 fields that were not controlled by metalaxyl were identified as A2 mating types with Gpi genotypes of $100 / 111$ and $111 / 122$. In 1994, US-1 was identified early in the season, but US-8 was soon predominant, especially in central Wisconsin, the primary production area of the state. In 1995, the south and central parts of the state were dominated by US- 8 , and both US- 1 and US- 8 were present in the northcentral and northeastern parts of the state. A recent shift in the population of $P$. infestans from an A1 mating type, metalaxyl-sensitive population to A2 mating type, metalaxyl-resistant genotypes has been noted in other regions $(4,7,15)$. Data pre-

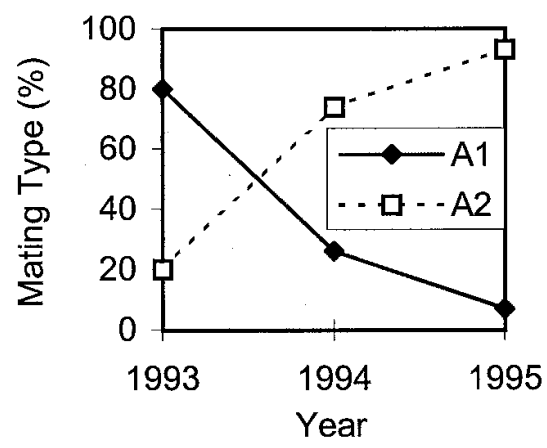

Fig. 1. Mating type frequencies of Wisconsin isolates of Phytophthora infestans from 1993 to 1995. Mating type was determined by pairing an unknown isolate with known A1 and A2 mating type isolates in 1993 and 1994. Mating type was determined based on the Glucose-6phosphate isomerase genotype of isolates in 1995. 
sented in this paper indicate that this displacement is occurring in Wisconsin as well.

Prior to 1993, Wisconsin experienced periodic outbreaks of late blight that were effectively managed with the use of protectant fungicides in combination with metalaxyl. All isolates obtained and tested before 1993 were identified as the US-1 genotype. Since the introduction of US-8, it has not been possible to control late blight with metalaxyl. With both mating types present in adjacent fields, there is now the possibility of sexual reproduction and oospore production, although no oospores or new genotypes have been observed. To determine whether both mating types were present in the same field, several isolates were cultured from plants at the same location at several times. In most cases, multiple isolates from the same field were the same mating type. However, two isolates of the opposite mating type were obtained from a single field in which the sample collection dates were separated by an application of metalaxyl. Additionally, detection of only US-1 and US-8 during 1994 and 1995 in Wisconsin suggests that asexual reproduction is the only means of propagation at this time. There is no evidence, to date, suggesting that sexual reproduction has occurred. If oospores are produced, $P$. infestans may overwinter in the soil without living host tissue and serve as another source of primary inoculum in the spring. Sexual reproduction also would generate greater genetic diversity in the population, which might lead to more aggressive and difficult to control genotypes (6).

\section{ACKNOWLEDGMENTS}

This work was supported by funding from the Wisconsin Potato Industry Board and the University of Wisconsin-Madison College of Agricultural and Life Sciences, Hatch Project 2885.

\section{LITERATURE CITED}

1. Caten, C. E., and Jinks, J. L. 1968. Spontaneous variability of single isolates of Phytophthora infestans. I. Cultural variation. Can. J. Bot. 46:329-348

2. Davidse, L. C., Looijen, D., Turkensteen, L. J., and van Der Wal, D. 1981. Occurrence of metalaxyl-resistant strains of Phytophthora infestans in Dutch potato fields. Neth. J. Plant Pathol. 87:65-68.

3. Deahl, K. L., Goth, R. W., Young, R., Sinden, S. L., and Gallegly, M. E. 1991. Occurrence of the A2 mating type of Phytophthora infestans in potato fields in the United States and Canada. Am. Potato J. 68:717-725.

4. Drenth, A. 1994. Molecular genetic evidence for a new sexually reproducing population of Phytophthora infestans in Europe. Ph.D. thesis. Wageningen Agricultural University, Wageningen, Netherlands.

5. Fry, W. E., Drenth, A., Spielman, L. J., Mantel, B. C., Davidse, L. C., and Goodwin, S. B. 1991. Population genetic structure of Phytophthora infestans in the Netherlands. Phytopathology 81:1330-1336.

6. Fry, W. E., Goodwin, S. B., Dyer, A. T., Matuszak, J. M., Drenth, A., Tooley, P. W., Sujkowski, L. S., Koh, Y. L., Cohen, B. A., Spielman, L. J., Deahl, K. L., Inglis, D. A., and Sandlan, K. P. 1993. Historical and recent migrations of Phytophthora infestans: Chronology, pathways, and implications. Plant Dis. 77:653-661.

7. Goodwin, S. B., Cohen, B. A., Deahl, K. L., and Fry, W. E. 1994. Migration from northern Mexico as the probable cause of recent genetic changes in populations of Phytophthora infestans in the United States and Canada. Phytopathology 84:553-558.

8. Goodwin, S. B., Cohen, B. A., and Fry, W. E.
1994. Panglobal distribution of a single clonal lineage of the Irish potato famine fungus. Proc. Natl. Acad. Sci. USA 91:11591-11595.

9. Goodwin, S. B., Drenth, A., and Fry, W. E. 1992. Cloning and genetic analyses of two highly polymorphic, moderately repetitive nuclear DNAs from Phytophthora infestans. Curr. Genet. 22:107-115.

10. Goodwin, S. B., and Fry, W. E. 1994. Genetic analyses of interspecific hybrids between Phy tophthora infestans and Phytophthora mirabilis. Exp. Mycol. 18:20-32.

11. Goodwin, S. B., Schneider, R. E., and Fry, W. E. 1995. Use of cellulose-acetate electrophoresis for rapid identification of allozyme genotypes of Phytophthora infestans. Plant Dis. 79:1181-1185.

12. Goodwin, S. B., Sujkowski, L. S., Dyer, A. T., Fry, B. A., and Fry, W. E. 1995. Direct detection of gene flow and probable sexual reproduction of Phytophthora infestans in northern North America. Phytopathology 85:473-479.

13. Shattock, R. C. 1988. Studies on the inheritance of resistance to metalaxyl in Phytophthora infestans. Plant Pathol. 37:4-11.

14. Shattock, R. C., Shaw, D. S., Fyfe, A. M., Dunn, J. R., Loney, K. H., and Shattock, J. A. 1990. Phenotypes of Phytophthora infestans collected in England and Wales from 1985 to 1988: Mating type, response to metalaxyl and isoenzyme analysis. Plant Pathol. 39:242-248.

15. Spielman, L. J., Drenth, A., Davidse, L. C., Sujkowski, L. J., Gu, W., Tooley, P. W., and Fry, W. E. 1991. A second world-wide migration and population displacement of Phytophthora infestans? Plant Pathol. 40:422-430.

16. Therrien, C. D., Tooley, P. W., Spielman, L. J., Fry, W. E., Ritch, D. L., and Shelly, S. E 1993. Nuclear DNA content, allozyme phenotypes and metalaxyl sensitivity of Phy tophthora infestans from Japan. Mycol. Res. 97:945-950.

17. Tooley, P. W., Fry, W. E., and Villareal Gonzalez, M. J. 1985. Isozyme characterization of sexual and asexual Phytophthora infestans populations. J. Hered. 76:431-435. 